\title{
Fixed point and common fixed point theorems on ordered cone b-metric space over Banach algebra
}

\author{
Sharafat Hussain \\ Department Mathematics, Quaid i Azam University, Islamabad, Pakistan. \\ Department of Mathematics, Women University of Azad Jammu and Kashmir Bagh, AJK, Pakistan.
}

\begin{abstract}
In this work, we obtain some fixed point and common fixed point theorems of comparable maps satisfying certain contractive conditions on partially ordered cone b-metric space over Banach algebras. Some examples are also provided to illustrate the main results presented in this paper, which extend and generalize several known results in cone b-metric spaces.
\end{abstract}

Keywords: Fixed point, partially ordered set, cone b-metric space, Banach algebra.

2010 MSC: 47H10, 54H25.

(C)2020 All rights reserved.

\section{Introduction}

In 2007, Huang and Zhang [13] introduced the notion of cone metric space, where they studied the convergence of a sequence in cone metric spaces in order to introduce completeness and proved some fixed point theorems for contractive maps on these spaces. They start the study of fixed point theorems in such spaces. Several authors published many papers on cone metric space, see, [1, 10, 16, 21, 25]. Later on, Rezapour and Hamlbarani [23] obtained some fixed point theorems by omitting the assumption of normality in the results of [13]. Recently, some authors, (see, e.g., [8, 10, 16, 22]) shown that the fixed point results obtained in cone metric space are equivalent to fixed point results in metric space. In 2013, Liu and $\mathrm{Xu}$ [20] introduced the notion of cone metric space over Banach algebra and defined generalized Lipschitz contraction with vector contractive coefficient instead of usual real constant. They proved the existence of fixed points with the assumption that the underlying cone is normal, futhermore they explained by an example that fixed point theorems in cone metric spaces over Banach algebra are not equivalent to those in metric spaces, and so, such generalizations are the genunie ones. In 2014, Xu and Radenovic [26] showed that the normality of cone can be removed from the results of Liu and $\mathrm{Xu}$ [20].

The idea of b-metric was initiated from the works of Bourbaki [7] and Bakhtin [5]. Czerwik [9] gave an axiom which was weaker than the triangular inequality and formally defined a b-metric space with

Email address: sharafat185@gmail.com (Sharafat Hussain)

doi: $10.22436 /$ jnsa.013.01.03 
a view of generalizing the Banach contraction mapping theorem. There exist many examples in the literature showing that the class of b-metric is effectively larger than that of metric spaces. By using the concept of b-metric space and cone metric space Hussain and Shah [15] introduced the notion of cone b-metric space. Later on, Huanga and Radenovic [12] introduced the concept of cone b-metric space over Banach algebra and present some common fixed point theorems in such spaces.

On the other hand fixed point theory on partially ordered sets has also been developing [3, 4, 11]. In the past several years, some existence results of fixed points for some contractive type maps in partially ordered cone metric spaces over Banach algebra were investigated. In this paper, we obtain some fixed point and common fixed point theorems of comparable maps satisfying certain contractive conditions on partially ordered cone b-metric space over Banach algebras. Some examples are also provided to illustrate the main results presented in this paper, which extend and generalize several known results in cone b-metric spaces.

\section{Preliminaries}

In this section, we recall some basic definitions and results about cone b-metric space and Banach algebras.

Definition 2.1 ([19]). A real Banach space $A$ is called real Banach algebra if for all $x, y, z \in A, a \in \mathbb{R}$, following properties holds:

(1) $x(y z)=(x y) z$

(2) $x(y+z)=x y+x z$ and $(x+y) z=x z+y z$;

(3) $a(x y)=(a x) y=x(a y)$;

(4) $\|x y\| \leqslant\|x\|\|y\|$.

Throughout this paper, we shall assume that a Banach algebra $A$ has a unit, i.e., multiplicative identity $e$ such that for all $x \in A$, ex $=x e$. An element $x \in A$ is said to be invertible if there exists an element $y \in A$ such that $x y=y x=e, y$ is called inverse of $x$ and denoted by $x^{-1}$. For more details see [24].

Proposition 2.2 ([24]). Let $A$ be a Banach algebra with a unit e, and $x \in A$. If the spectral radius $r(x)$ of $x$ is less than 1, i.e.,

$$
r(x)=\lim _{n \rightarrow \infty}\left\|x^{n}\right\|^{\frac{1}{n}}=\inf _{n \geqslant 1}\left\|x^{n}\right\|^{\frac{1}{n}}<1,
$$

then $\mathrm{e}-\mathrm{x}$ is invertible. Actually,

$$
(e-x)^{-1}=\sum_{i=0}^{\infty} x^{i} .
$$

Remark 2.3 ([24]). Let A be a Banach algebra with a unit e then the spectral radius $r(x)$ of $x$ satisfies

$$
r(x) \leqslant\|x\|
$$

for all $x \in A$.

Remark 2.4. If the condition $r(x)<1$ is replaced by $\|x\| \leqslant 1$, in the Proposition 2.2, then the conclusion remain true.

Definition 2.5 ([3]). A subset $P$ of a Banach algebra $A$ is called cone of $A$ if

(1) $\mathrm{P}$ is non empty and closed and $\{\theta, e\} \subset \mathrm{P}$;

(2) for all non negative real numbers $a, b, a P+b P \subset P$;

(3) $\mathrm{P}^{2}=\mathrm{PP} \subset \mathrm{P}$;

(4) $\mathrm{P} \cup(-) \mathrm{P}=\{\theta\}$, 
where $\theta$ denotes the null of the Banach algebra $A$.

For a given cone $P \subset A$, we can define a partial ordering $\preceq$ with respect to $P$ by $x \preceq y$ if and only if $y-x \in P$. $x \prec y$ will stand for $x \preceq y$ and $x \neq y$, while $x \ll y$ will stand for $y-x \in \operatorname{int}(P)$, where int $(P)$ denotes the interior of $P$. If $\operatorname{int}(P) \neq \theta$, then $P$ is called a solid cone. The cone $P$ is called normal if there is a number $M>0$ such that, for all $x, y \in A$

$$
\theta \preceq x \preceq y \Longrightarrow\|x\| \leqslant M\|y\| .
$$

The least positive number satisfying above is called normal constant of $P$ (see [13]). Note that, for any normal cone $P$ we have $M \geqslant 1$ (see [2]).

Definition 2.6 ([20]). Let $X$ be a nonempty set. A mapping $d: X \times X \rightarrow A$ is called a cone metric on $X$, if for all $x, y, z \in X$ it satisfies the following

(1) $\theta \preceq d(x, y)$ and $d(x, y)=\theta$ if and only if $x=y$;

(2) $d(x, y)=d(y, x)$;

(3) $d(x . z) \preceq d(x, y)+d(x, y)$.

$(X, d)$ is called cone metric space over the Banach algebra A.

Definition 2.7 ([12]). Let $X$ be a nonempty set. A mapping $d: X \times X \rightarrow A$ is called a cone $b$-metric on $X$, if for all $x, y, z \in X$ and $s \geqslant 1$ being a constant it satisfies the following

(1) $\theta \preceq d(x, y)$ and $d(x, y)=\theta$ if and only if $x=y$;

(2) $d(x, y)=d(y, x)$;

(3) $d(x . z) \preceq s[d(x, y)+d(y, z)]$.

$(X, d, s)$ is called cone b-metric space over the Banach algebra A.

Example 2.8 ([12]). Let $A=C[a, b]$ be the set of continuous on the interval $[a, b]$ with supremum norm. Define multiplication in the usual way. Then $A$ is Banach algebra with a unit 1 . Let $P=\{x \in A: x(t) \geqslant$ $0, t \in[a, b]\}$ and $X=\mathbb{R}$. Define a mapping $d: X \times X \rightarrow A$ by $d(x, y)(t)=|x-y|^{p} e^{t}$ for all $x, y \in X$, where $p>1$ is a constant. Then $(X, d, s)$ is cone $b$-metric space with $s=2^{p-1}$. Note that it is not cone metric space.

Definition $2.9([12])$. Let $(X, d, s)$ be a cone b-metric space over a Banach algebra $A, x \in X$ and $\left\{x_{n}\right\}$ be a sequence in $X$. Then

(1) the sequence $\left\{x_{n}\right\}$ converges to $x$ whenever for each $c \in A$ with $\theta \ll c$, there is $n_{0} \in \mathbb{N}$ such that $d\left(x_{n}, x\right) \ll c$ for all $n>n_{0}$, we denote this by $\lim _{n \rightarrow \infty} x_{n}=x$ or $x_{n} \rightarrow x$ as $n \rightarrow \infty$;

(2) the sequence $\left\{x_{n}\right\}$ is a Cauchy sequence whenever for each $c \in A$ with $\theta \ll c$, there is $n_{0} \in \mathbb{N}$ such that $d\left(x_{n}, x_{m}\right) \ll c$ for all $n, m>n_{0}$;

(3) a cone b-metric space is called complete if every Cauchy sequence is convergent in $X$.

It is obvious that the limit of convergent sequence in a cone b-metric space is unique. A mapping $T: X \rightarrow X$ is called continuous at $x \in X$, if for every sequence $\left\{x_{n}\right\}$ in $X$ such that $x_{n} \rightarrow x$ as $n \rightarrow \infty$, we have $T x_{n} \rightarrow T x$ as $n \rightarrow \infty$.

Definition 2.10 ([17]). Let $P$ be a solid cone in a Banach algebra $A$. A sequence $\left\{x_{n}\right\}$ in $P$ is said to be a c-sequence if for each $c \gg \theta$ there exists a natural number $N$ such that $x_{n} \ll c$ for all $n>N$.

Lemma 2.11 ([26]). Let $\mathrm{P}$ be a solid cone in a Banach algebra $A,\left\{x_{n}\right\}$ and $\left\{y_{n}\right\}$ be two c-sequences in $P$. If $\alpha, \beta \in P$ are two arbitrarily given vectors, then $\left\{\alpha x_{n}+\beta y_{n}\right\}$ is a c-sequence.

Lemma 2.12 ([21]). If $\mathrm{E}$ is real Banach space with a cone $\mathrm{P}$ and if $\mathrm{a} \preceq \mu \mathrm{a}$ with $\mathrm{a} \in \mathrm{P}$ and $0 \leqslant \mu \leqslant 1$, then $\mathrm{a}=\theta$. 
Lemma 2.13 ([21]). If $\mathrm{E}$ is real Banach space with a solid cone $\mathrm{P}$ and if $\theta \preceq \mathrm{u} \ll \mathrm{c}$ for each $\theta \ll \mathrm{c}$, then $\mathrm{u}=\theta$.

Lemma 2.14 ([21]). If $\mathrm{E}$ is real Banach space with a solid cone $\mathrm{P}$ and if $\left\|\mathrm{x}_{\mathrm{n}}\right\| \rightarrow 0(\mathrm{n} \rightarrow \infty)$, then for any $\theta \ll \mathrm{c}$, there exists $\mathrm{N} \in \mathbb{N}$ such that, for any $\mathrm{n}>\mathrm{N}$, we have $\mathrm{x}_{\mathrm{n}} \ll \mathrm{c}$.

Lemma 2.15 ([26]). Let $A$ be a Banach algebra and if $x y=y x$ for all $x, y \in A$, then following hold:

(i) $r(x y) \leqslant r(x) r(y)$;

(ii) $r(x+y) \leqslant r(x)+r(y)$;

(iii) $|r(x)-r(y)| \leqslant r(x-y)$.

Lemma 2.16 ([26]). Let $\mathrm{A}$ be a Banach algebra and $\mathrm{k}$ be vector in $\mathrm{A}$. If $0 \leqslant \mathrm{r}(\mathrm{k})<1$, then we have

$$
r\left((e-k)^{-1}\right) \leqslant(1-r(k))^{-1} .
$$

Definition $2.17([3])$. Let $(X, \sqsubseteq)$ be a partially ordered set. Two elements $x, y \in X$ are said to be comparable if $x \sqsubseteq y$ or $y \sqsubseteq x$ hold. Similarly, $T: X \rightarrow X$ is called comparable if for any comparable pair $x, y \in X, T x$ and $\mathrm{Ty}$ are comparable.

Remark 2.18. A map $T: X \rightarrow X$ is said to be non decreasing with $\sqsubseteq$, if for any $x, y \in X, x \sqsubseteq y$, then $T x \sqsubseteq$ Ty. Note that, a comparable map may not be non decreasing with $\sqsubseteq$.

Definition 2.19 ([3]). Let $(X, \sqsubseteq)$ be a partially ordered set. Two maps $T, S: X \rightarrow X$ are said to be weakly comparable if both $\mathrm{T} x, \mathrm{ST} x$ and $S x, \mathrm{TS} x$ are comparable for any $x \in X$.

Theorem 2.20 ([27]). Let $(X, \sqsubseteq)$ be a partially ordered set and $(X, d)$ be a cone metric space over a Banach algebra A. Suppose that $\mathrm{T}: \mathrm{X} \rightarrow \mathrm{X}$ is continious and comparable and following properties hold:

(i) there exists $\mathrm{k} \in \mathrm{P}$ with $\mathrm{r}(\mathrm{k}) \in(0,1)$ such that $\mathrm{d}(\mathrm{T} x, \mathrm{~T} y) \preceq \mathrm{kd}(\mathrm{x}, \mathrm{y})$ for any comparable pair $\mathrm{x}, \mathrm{y} \in \mathrm{X}$;

(ii) there exists $\mathrm{x}_{0} \in \mathrm{X}$ such that $\mathrm{x}_{0}$ and $\mathrm{T} \mathrm{x}_{0}$ are comparable.

Then $\mathrm{T}$ has a fixed point in $\mathrm{X}$.

\section{Main results}

In this section we establish some fixed point and common fixed point results of comparable maps satisfying certain contractive conditions on partially ordered cone b-metric spaces over Banach algebras where underlying cone $\mathrm{P}$ is solid and not necessarily normal.

Theorem 3.1. Let $(\mathrm{X}, \sqsubseteq)$ be a partially ordered set and $(\mathrm{X}, \mathrm{d})$ be a complete cone b-metric space over a Banach algebra $\mathrm{A}$ with coefficient $\mathrm{s} \geqslant 1$. Suppose that $\mathrm{T}: \mathrm{X} \rightarrow \mathrm{X}$ is continuous and comparable. Assume that the following hold:

(i) there exists $\alpha \in \mathrm{P}$ with $\mathrm{r}(\alpha)<\frac{1}{1+\mathrm{s}}$ such that $\mathrm{d}(\mathrm{T} x, \mathrm{Ty}) \preceq \alpha[\mathrm{d}(\mathrm{T} x, \mathrm{x})+\mathrm{d}(\mathrm{T} y, y)]$ for any comparable pair $x, y \in X$

(ii) there exists $\mathrm{x}_{0} \in \mathrm{X}$ such that $\mathrm{x}_{0}$ and $\mathrm{T} \mathrm{x}_{0}$ are comparable.

Then $\mathrm{T}$ has a fixed point in $\mathrm{X}$.

Proof. Let $x_{0} \in X$ be an arbitrary point. If $T x_{0}=x_{0}$, then the proof is finished. Assume that $T x_{0} \neq x_{0}$. From condition (ii) and $T$ being comparable, we deduce that for any $j \geqslant 1, T^{j} \chi_{0}$ and $T^{j+1} \chi_{0}$ are comparable. Let $\mathrm{T}^{\mathrm{n}} \mathrm{x}_{0}=\mathrm{x}_{\mathrm{n}}$, we yield $\mathrm{x}_{\mathfrak{j}}$ and $\mathrm{x}_{\mathfrak{j}+1}$ are comparable. From condition (i), we have

$$
d\left(x_{n+1}, x_{n}\right)=d\left(T x_{n}, T x_{n-1}\right) \preceq \alpha\left[d\left(x_{n}, T x_{n}\right)+d\left(x_{n-1}, T x_{n-1}\right)=\alpha\left[d\left(x_{n}, x_{n+1}\right)+d\left(x_{n-1}, x_{n}\right) .\right.\right.
$$

Since $r(\alpha)<\frac{1}{1+s}$, it follows from Proposition 2.2 that $(e-\alpha)$ is invertible. Hence by (3.1), we deduce that

$$
d\left(x_{n+1}, x_{n}\right) \preceq(e-\alpha)^{-1} \alpha d\left(x_{n}, x_{n-1}\right) .
$$


By putting $(e-\alpha)^{-1} \alpha=k$, we get

$$
d\left(x_{n+1}, x_{n}\right) \preceq k d\left(x_{n}, x_{n-1}\right) .
$$

By repeating this relation we yield,

$$
d\left(x_{n+1}, x_{n}\right) \preceq k^{n} d\left(x_{1}, x_{0}\right) .
$$

By Lemma 2.15 and Lemma 2.16, we obtain

$$
r(k)=r\left((e-\alpha)^{-1} \alpha\right) \leqslant \frac{r(\alpha)}{(1-r(\alpha))}<\frac{\frac{1}{1+s}}{1-\frac{1}{1+s}}=\frac{1}{s} .
$$

Note that $r(k)<\frac{1}{s}$ implies that $(e-s k)$ is invertible and

$$
(e-s k)^{-1}=\sum_{i=0}^{\infty}(s k)^{i} .
$$

Now, for $m>n$ we have

$$
\begin{aligned}
\mathrm{d}\left(x_{m}, x_{n}\right) \preceq & s d\left(x_{n}, x_{n+1}\right)+s^{2} d\left(x_{n+1}, x_{n+2}\right)+\cdots+s^{m-n-1} d\left(x_{m-2}, x_{m-1}\right)+s^{m-n-1} d\left(x_{m-1}, x_{m}\right) \\
& \preceq s k^{n} d\left(x_{1}, x_{0}\right)+s^{2} k^{n+1} d\left(x_{1}, x_{0}\right)+\cdots+s^{m-n-1} k^{m-2} d\left(x_{1}, x_{0}\right)+s^{m-n-1} k^{m-1} d\left(x_{1}, x_{0}\right) \\
& =s k^{n} d\left(x_{1}, x_{0}\right)\left[e+s k+(s k)^{2}+\cdots+(s k)^{m-1}\right] \\
& \preceq \sum_{i=0}^{\infty}(s k)^{i}\left(s k^{n}\right) d\left(x_{1}, x_{0}\right)=(e-s k)^{-1}\left(s k^{n}\right) d\left(x_{1}, x_{0}\right) .
\end{aligned}
$$

Since $r(k)<\frac{1}{s} \leqslant 1$ implies that $\left\|k^{n}\right\| \rightarrow 0(n \rightarrow \infty)$, further, $\left\{k^{n}\right\}$ is a c-sequence. Thus from Lemma 2.11 we get that $\left\{s k^{n}(e-s k)^{-1} d\left(x_{1}, x_{0}\right)\right\}$ is a c-sequence, which shows that $\left(x_{n}\right)$ is a Cauchy sequence. Since $X$ is complete so there exists $z \in X$ such that $x_{n} \rightarrow z$ as $n \rightarrow \infty$. By the continuity of $T$ we conclude that $z$ is fixed point of $\mathrm{T}$.

Some generalizations of the results are given in the following. If we remove the continuity from Theorem 3.1 we obtained the the following theorem.

Theorem 3.2. Let $(\mathrm{X}, \sqsubseteq)$ be a partially ordered set and $(\mathrm{X}, \mathrm{d})$ be a complete cone b-metric space over a Banach algebra $\mathrm{A}$ with coefficient $\mathrm{s} \geqslant 1$. Suppose that $\mathrm{T}: \mathrm{X} \rightarrow \mathrm{X}$ is comparable and following properties hold:

(i) there exists $\alpha \in \mathrm{P}$ with $\mathrm{r}(\alpha)<\frac{1}{1+\mathrm{s}}$ such that $\mathrm{d}(\mathrm{T} x, \mathrm{~T} y) \preceq \alpha[\mathrm{d}(\mathrm{T} x, \mathrm{x})+\mathrm{d}(\mathrm{T} y, y)]$ for any comparable pair $x, y \in X$

(ii) there exists $\mathrm{x}_{0} \in \mathrm{X}$ such that $\mathrm{x}_{0}$ and $\mathrm{T} \mathrm{x}_{0}$ are comparable;

(iii) if a sequence $\left\{x_{n}\right\}$ converges to $x \in X$ and for all $j \geqslant 0, x_{j}$ and $x_{j+1}$ are comparable, then $x_{j}$ and $x$ are comparable.

Then $\mathrm{T}$ has a fixed point in $\mathrm{X}$.

Proof. Let $\mathrm{T}^{\mathrm{n}} \mathrm{x}_{0}=\mathrm{x}_{\mathrm{n}}$. From the proof of Theorem 3.1 it follows that $\mathrm{x}_{n}, \mathrm{x}_{\mathrm{n}+1}$ are comparable for all $n \geqslant 0$ and $x_{n}$ converges to $z$. Now from condition (iii) $x_{n}, z$ are comparable. So from condition (i) we have

$$
\mathrm{d}(\mathrm{T} z, z) \preceq \mathrm{s}\left[\mathrm{d}\left(\mathrm{T} z, T x_{n}\right)+\mathrm{d}\left(\mathrm{T} x_{n}, z\right)\right] \preceq \mathrm{s} \alpha\left[\mathrm{d}(z, \mathrm{~T} z)+\mathrm{d}\left(x_{n}, T x_{n}\right)\right]+\operatorname{sd}\left(T x_{n}, z\right) .
$$

Since $e-s \alpha$ is invertible, then from above equation we have

$$
\mathrm{d}(\mathrm{T} z, z) \preceq s(e-s \alpha)^{-1}\left[\alpha \mathrm{d}\left(x_{n}, x_{n+1}\right)+\mathrm{d}\left(x_{n+1}, z\right)\right] .
$$

Because $\left\{x_{n}\right\}$ is Cauchy and convergent; it means $\left\{d\left(x_{n}, x_{n+1}\right)\right\}$ and $\left\{d\left(x_{n+1}, z\right)\right\}$ are c-sequences. Hence from Lemma 2.11, $\left\{s(e-s \alpha)^{-1}\left[\alpha d\left(x_{n}, x_{n+1}\right)+d\left(x_{n+1}, z\right)\right]\right\}$ is also c-sequence. So $d(T z, z)=\theta$, which implies that $z$ is a fixed point of $T$. 
Corollary 3.3. Let $(X, \sqsubseteq)$ be a partially ordered set and $(X, d)$ be a complete cone metric space over a Banach algebra A. Suppose that $\mathrm{T}: \mathrm{X} \rightarrow \mathrm{X}$ is continuous and comparable and following properties hold:

(i) there exists $\alpha \in \mathrm{P}$ with $\mathrm{r}(\alpha)<\frac{1}{2}$ such that $\mathrm{d}(\mathrm{Tx}, \mathrm{Ty}) \preceq \alpha[\mathrm{d}(\mathrm{Tx}, \mathrm{x})+\mathrm{d}(\mathrm{T} y, y)]$ for any comparable pair $x, y \in X$

(ii) there exists $\mathrm{x}_{0} \in \mathrm{X}$ such that $\mathrm{x}_{0}$ and $\mathrm{T} \mathrm{x}_{0}$ are comparable.

Then $\mathrm{T}$ has a fixed point in $\mathrm{X}$.

Proof. Take $\mathrm{s}=1$ in Theorem 3.1 .

Corollary 3.4. Let $(\mathrm{X}, \sqsubseteq)$ be a partially ordered set and $(\mathrm{X}, \mathrm{d})$ be a complete cone metric space over a Banach algebra A. Suppose that $\mathrm{T}: \mathrm{X} \rightarrow \mathrm{X}$ is comparable and following properties hold:

(i) there exists $\alpha \in \mathrm{P}$ with $\mathrm{r}(\alpha)<\frac{1}{2}$ such that $\mathrm{d}(\mathrm{Tx}, \mathrm{Ty}) \preceq \alpha[\mathrm{d}(\mathrm{Tx}, \mathrm{x})+\mathrm{d}(\mathrm{T} y, y)]$ for any comparable pair $x, y \in X$

(ii) there exists $\mathrm{x}_{0} \in \mathrm{X}$ such that $\mathrm{x}_{0}$ and $\mathrm{T} \mathrm{x}_{0}$ are comparable;

(iii) if a sequence $\left\{x_{n}\right\}$ converges to $x \in X$ and for all $j \geqslant 0, x_{j}$ and $x_{j+1}$ are comparable, then $x_{j}$ and $x$ are comparable.

Then $\mathrm{T}$ has a fixed point in $\mathrm{X}$.

Proof. Take $s=1$ in Theorem 3.2.

Example 3.5. Let $X=\{1,2,3\}$ and $A=C_{\mathbb{R}}^{1}[0,1]$ with norm $\|x\|=\|x\|_{\infty}+\left\|x^{\prime}\right\|_{\infty}$ and multiplication as usual pointwise multiplication. $A$ is Banach Algebra with $e=1$. Consider the non normal cone $P=\{x(t): x(t) \geqslant 0$ for $t \in[0,1]\}$. Define a mapping $d: X \times X \rightarrow A$ by $d(1,2)=d(2,1)=d(2,3)=d(3,2)=$ $e^{\mathrm{t}}, \mathrm{d}(1,3)=\mathrm{d}(3,1)=3 e^{\mathrm{t}}, \mathrm{d}(1,1)=\mathrm{d}(2,2)=\mathrm{d}(3,3)=0$. Then $(X, \mathrm{~d})$ is a cone b-metric space over Banach algebra with $s=\frac{3}{2}$ but not Cone metric space because $3 e^{t}=d(1,3) \npreceq d(1,2)+d(2,3)=2 e^{t}$. Define mapping $\mathrm{T}: \mathrm{X} \rightarrow \mathrm{X}$ and partial order on $\mathrm{X}$ as follows:

$$
\mathrm{T} 1=\mathrm{T} 2=2, \mathrm{~T} 3=1
$$

and $\sqsubseteq=\{(1,1),(2,2),(3,3)(1,2),(2,1),(1,3),(3,1)\}$. Then $d(T x, T y) \preceq \alpha[d(T x, x)+d(T y, y)]$ for any comparable pair $x, y \in X$; with $\alpha(t)=\frac{t}{8}+\frac{1}{4}$. Here, $r(\alpha(t))=\frac{3}{8}<\frac{1}{1+s}=\frac{2}{5}$. All the conditions of Theorem 3.1 are satisfies and 2 is fixed point of $T$.

Theorem 3.6. Let $(\mathrm{X}, \sqsubseteq)$ be a partially ordered set and $(\mathrm{X}, \mathrm{d})$ be a complete cone b-metric space over a Banach algebra $\mathrm{A}$ with coefficient $\mathrm{s} \geqslant 1$. Suppose that $\mathrm{T}: \mathrm{X} \rightarrow \mathrm{X}$ is continuous and comparable and following properties hold:

(i) there exists $\alpha \in \mathrm{P}$ with $\mathrm{r}(\alpha)<\frac{1}{\mathrm{~s}+\mathrm{s}^{2}}$ such that $\mathrm{d}(\mathrm{Tx}, \mathrm{Ty}) \preceq \alpha[\mathrm{d}(\mathrm{T} x, \mathrm{y})+\mathrm{d}(\mathrm{Ty}, \mathrm{x})]$ for any comparable pair $x, y \in X$;

(ii) there exists $\mathrm{x}_{0} \in \mathrm{X}$ such that $\mathrm{x}_{0}$ and $\mathrm{T} \mathrm{x}_{0}$ are comparable.

Then $\mathrm{T}$ has a fixed point in $\mathrm{X}$.

Proof. Let $x_{0} \in X$ be an arbitrary point. If $T x_{0}=x_{0}$, then the proof is finished. Assume that $T x_{0} \neq x_{0}$. From condition (ii) and $T$ is comparable, we deduce that for any $j \geqslant 1, T^{j} x_{0}$ and $T^{j+1} x_{0}$ are comparable. Let $T^{n} x_{0}=x_{n}$, we yield $x_{j}$ and $x_{j+1}$ are comparable. From condition (i), we have

$$
\begin{aligned}
d\left(x_{n+1}, x_{n}\right)= & d\left(T x_{n}, T x_{n-1}\right) \preceq \alpha\left[d\left(T x_{n}, x_{n-1}\right)+d\left(x_{n}, T x_{n-1}\right)\right. \\
& =\alpha\left[d\left(x_{n+1}, x_{n-1}\right)+d\left(x_{n}, x_{n}\right) \preceq \alpha\left[\operatorname{sd}\left(x_{n+1}, x_{n}\right)+\operatorname{sd}\left(x_{n}, x_{n+1}\right) .\right.\right.
\end{aligned}
$$

Since $r(\alpha)<\frac{1}{s}$, it follows from Proposition 2.2 that $(e-s \alpha)$ is invertible. Hence by (3.2), we deduce that

$$
d\left(x_{n+1}, x_{n}\right) \preceq(e-s \alpha)^{-1} s \alpha d\left(x_{n}, x_{n-1}\right) .
$$


By putting $(e-s \alpha)^{-1} s \alpha=k$, we get

$$
d\left(x_{n+1}, x_{n}\right) \preceq \operatorname{kd}\left(x_{n}, x_{n-1}\right) .
$$

By repeating this relation we yield

$$
d\left(x_{n+1}, x_{n}\right) \preceq k^{n} d\left(x_{1}, x_{0}\right) .
$$

By Lemma 2.15 and Lemma 2.16, we obtain

$$
r(k)=r\left((e-s \alpha)^{-1} s \alpha\right) \leqslant \frac{r(s \alpha)}{(1-r(s \alpha))}=\frac{s r(\alpha)}{(1-s r(\alpha))}<\frac{\frac{s}{s+s^{2}}}{1-\frac{s}{s+s^{2}}}=\frac{1}{s} .
$$

Note that $r(k)<\frac{1}{s}$ implies that $(e-s k)$ is invertible and

$$
(e-s k)^{-1}=\sum_{i=0}^{\infty}(s k)^{i} \text {. }
$$

Now, for $m>n$ we have

$$
\begin{aligned}
\mathrm{d}\left(x_{\mathrm{m}}, x_{\mathfrak{n}}\right) \preceq & s d\left(x_{n}, x_{n+1}\right)+s^{2} d\left(x_{n+1}, x_{n+2}\right)+\cdots+s^{m-n-1} d\left(x_{m-2}, x_{m-1}\right)+s^{m-n-1} d\left(x_{m-1}, x_{m}\right) \\
& \preceq s k^{n} d\left(x_{1}, x_{0}\right)+s^{2} k^{n+1} d\left(x_{1}, x_{0}\right)+\cdots+s^{m-n-1} k^{m-2} d\left(x_{1}, x_{0}\right)+s^{m-n-1} k^{m-1} d\left(x_{1}, x_{0}\right) \\
& =s k^{n} d\left(x_{1}, x_{0}\right)\left[e+s k+(s k)^{2}+\cdots+(s k)^{m-1}\right] \\
& \preceq \sum_{i=0}^{\infty}(s k)^{i}\left(s k^{n}\right) d\left(x_{1}, x_{0}\right)=(e-s k)^{-1}\left(s k^{n}\right) d\left(x_{1}, x_{0}\right) .
\end{aligned}
$$

Since $r(k)<\frac{1}{s} \leqslant 1$ implies that $\left\|k^{n}\right\| \rightarrow 0(n \rightarrow \infty)$, further, $\left\{k^{n}\right\}$ is a c-sequence. Thus from Lemma 2.11 we get that $\left\{\mathrm{sk}^{\mathrm{n}}(e-s k)^{-1} \mathrm{~d}\left(\mathrm{x}_{1}, x_{0}\right)\right\}$ is a c-sequence. Which shows that $\left(x_{n}\right)$ is a Cauchy sequence. Since $X$ is complete so there exists $z \in X$ such that $x_{n} \rightarrow z$ as $n \rightarrow \infty$. By the continuity of $T$ we conclude that $z$ is fixed point of $T$.

If we remove the continuity from Theorem 3.6 we obtained the the following theorem.

Theorem 3.7. Let $(\mathrm{X}, \sqsubseteq)$ be a partially ordered set and $(\mathrm{X}, \mathrm{d})$ be a complete cone b-metric space over a Banach algebra $\mathrm{A}$ with coefficient $\mathrm{s} \geqslant 1$. Suppose that $\mathrm{T}: \mathrm{X} \rightarrow \mathrm{X}$ is comparable and following properties hold:

(i) there exists $\alpha \in \mathrm{P}$ with $\mathrm{r}(\alpha)<\frac{1}{\mathrm{~s}+\mathrm{s}^{2}}$ such that $\mathrm{d}(\mathrm{T} x, \mathrm{Ty}) \preceq \alpha[\mathrm{d}(\mathrm{T} x, \mathrm{y})+\mathrm{d}(\mathrm{Ty}, \mathrm{x})]$ for any comparable pair $x, y \in X$

(ii) there exists $\mathrm{x}_{0} \in \mathrm{X}$ such that $\mathrm{x}_{0}$ and $\mathrm{T} \mathrm{x}_{0}$ are comparable;

(iii) if a sequence $\left\{x_{n}\right\}$ converges to $x \in X$ and for all $j \geqslant 0, x_{j}$ and $x_{j+1}$ are comparable, then $x_{j}$ and $x$ are comparable.

Then $\mathrm{T}$ has a fixed point in $\mathrm{X}$.

Proof. Let $\mathrm{T}^{\mathrm{n}} \mathrm{x}_{0}=\mathrm{x}_{\mathrm{n}}$. From the proof of Theorem 3.6 it follows that $\mathrm{x}_{\mathrm{n}}, \mathrm{x}_{\mathrm{n}+1}$ are comparable for all $\mathrm{n} \geqslant 0$ and $x_{n}$ converges to $z$. Now from condition (iii), $x_{n}, z$ are comparable. So from condition (i) we have

$$
\begin{aligned}
\mathrm{d}(\mathrm{T} z, z) \preceq \mathrm{s}\left[\mathrm{d}\left(\mathrm{T} z, T x_{n}\right)+\mathrm{d}\left(\mathrm{T} x_{n}, z\right)\right] & \preceq \mathrm{s} \alpha\left[\mathrm{d}\left(z, T x_{n}\right)+\mathrm{d}\left(x_{n}, T z\right)\right]+\mathrm{sd}\left(\mathrm{T} x_{n}, z\right) \\
& \preceq \mathrm{s} \alpha\left[\mathrm{d}\left(z, x_{n+1}\right)+\mathrm{d}\left(x_{n}, T z\right)\right]+\operatorname{sd}\left(x_{n+1}, z\right) \\
& \preceq \mathrm{s} \alpha\left[\mathrm{d}\left(z, x_{n+1}\right)+\operatorname{sd}\left(x_{n}, z\right)+\operatorname{sd}(z, T z)\right]+\operatorname{sd}\left(x_{n+1}, z\right) .
\end{aligned}
$$

From $r(\alpha)<\frac{1}{s+s^{2}}<\frac{1}{s^{2}}$ we find that $\left(e-s^{2} \alpha\right)$ is invertible, so from above equation we have

$$
\mathrm{d}(\mathrm{T} z, z) \preceq \mathrm{s}\left(e-s^{2} \alpha\right)^{-1}\left[(e+\alpha) \mathrm{d}\left(x_{\mathrm{n}+1}, z\right)+\mathrm{s} \alpha \mathrm{d}\left(x_{\mathrm{n}}, z\right)\right] .
$$

Because $\left\{x_{n}\right\}$ is Cauchy and convergent; it means $\left\{d\left(x_{n}, z\right)\right\}$ is c-sequences. Hence from Lemma 2.11, $\left\{s\left(e-s^{2} \alpha\right)^{-1}\left[(e+\alpha) d\left(x_{n+1}, z\right)+s \alpha d\left(x_{n}, z\right)\right]\right\}$ is also c-sequence. So $d(T z, z)=\theta$, which implies that $z$ is a fixed point of $T$. 
Corollary 3.8. Let $(\mathrm{X}, \sqsubseteq)$ be a partially ordered set and $(\mathrm{X}, \mathrm{d})$ be a complete cone metric space over a Banach algebra A. Suppose that $\mathrm{T}: \mathrm{X} \rightarrow \mathrm{X}$ is continuous and comparable and following properties hold:

(i) there exists $\alpha \in \mathrm{P}$ with $\mathrm{r}(\alpha)<\frac{1}{2}$ such that $\mathrm{d}(\mathrm{Tx}, \mathrm{Ty}) \preceq \alpha[\mathrm{d}(\mathrm{Tx}, \mathrm{y})+\mathrm{d}(\mathrm{Ty}, \mathrm{x})]$ for any comparable pair $x, y \in X$

(ii) there exists $x_{0} \in X$ such that $x_{0}$ and $T x_{0}$ are comparable.

Then $\mathrm{T}$ has a fixed point in $\mathrm{X}$.

Proof. Take $\mathrm{s}=1$ in Theorem 3.6.

Corollary 3.9. Let $(\mathrm{X}, \sqsubseteq)$ be a partially ordered set and $(\mathrm{X}, \mathrm{d})$ be a complete cone metric space over a Banach algebra A. Suppose that $\mathrm{T}: \mathrm{X} \rightarrow \mathrm{X}$ is comparable and following properties hold:

(i) there exists $\alpha \in \mathrm{P}$ with $\mathrm{r}(\alpha)<\frac{1}{2}$ such that $\mathrm{d}(\mathrm{Tx}, \mathrm{Ty}) \preceq \alpha[\mathrm{d}(\mathrm{T} x, y)+\mathrm{d}(\mathrm{T} y, x)]$ for any comparable pair $x, y \in X$

(ii) there exists $\mathrm{x}_{0} \in \mathrm{X}$ such that $\mathrm{x}_{0}$ and $\mathrm{T} \mathrm{x}_{0}$ are comparable;

(iii) if a sequence $\left\{x_{n}\right\}$ converges to $x \in X$ and for all $j \geqslant 0, x_{j}, x_{j+1}$ are comparable, then $x_{j}, x$ are comparable.

Then $\mathrm{T}$ has a fixed point in $\mathrm{X}$.

Proof. Take $\mathrm{s}=1$ in Theorem 3.7.

Example 3.10. Let $A=\mathbb{R}^{2}$. For each $\left(a_{1}, a_{2}\right) \in A$, let $\left\|\left(a_{1}, a_{2}\right)\right\|=\left|a_{1}\right|+\left|a_{2}\right|$. The multiplication is defined by

$$
a b=\left(a_{1}, a_{2}\right)\left(b_{1}, b_{2}\right)=\left(a_{1} b_{1}, a_{1} b_{2}+a_{2} b_{1}\right) .
$$

Then $A$ is Banach algebra with unit $e=(0,1)$.

Let $P=\left\{(a, b) \in \mathbb{R}^{2}: a, b \geqslant 0\right\}$ a normal cone in $A$. Let $X=\{1,2,3,4\}$ and define $d: X \times X \rightarrow A$ as follows: $\mathrm{d}(3,4)=\mathrm{d}(4,3)=(3,6), \mathrm{d}(1,4)=\mathrm{d}(4,1)=\mathrm{d}(3,1)=\mathrm{d}(3,1)=(1,2), \mathrm{d}(2,1)=\mathrm{d}(1,2)=(4,3)$, $d(2,3)=d(3,2)=d(3,4)=d(4,3)=d(2,4)=d(4,2)=(3,4), d(x, y)=\theta$ when $x=y$ for all $x, y \in X$. Then $(X, d)$ is cone $b$-metric space over Banach algebra $A$ with $s=\frac{3}{2}$ but not a cone metric space over Banach algebra $A$, since the triangular inequality does not hold. Define $T: X \rightarrow X$ and partial order on $X$ as below:

$$
\mathrm{T} 1=1, \mathrm{~T} 2=4, \mathrm{~T} 3=3, \mathrm{~T} 4=1
$$

and $\sqsubseteq=\{(1,1),(2,2),(3,3),(4,4),(1,2),(1,4),(4,2)\}$. Careful calculations show that $\mathrm{d}(\mathrm{T} x, \mathrm{~T} y) \preceq \alpha[\mathrm{d}(\mathrm{T} x, y)+$ $d(T y, x)]$ for any comparable pair $x, y \in X$ with $\alpha=\left(\frac{1}{4}, \beta\right)$, where $\beta$ is any positive real number. Of course

$$
r(\alpha)=\lim _{n \rightarrow \infty}\left\|\left(\frac{1}{4}, \beta\right)^{n}\right\|^{\frac{1}{n}}=\lim _{n \rightarrow \infty}\left\|\left(\frac{1}{4}\right)^{n}, \beta . n\left(\frac{1}{4}\right)^{n-1}\right\|^{\frac{1}{n}}=\frac{1}{4}<\frac{1}{s^{2}+s}=\frac{4}{15} .
$$

Condition (ii) of the Theorem 3.6 is also satisfied because $1 \sqsubseteq \mathrm{T} 1$. Therefore, by applying Theorem 3.6 we conclude that $\mathrm{T}$ has a fixed point.

Theorem 3.11. Let $(X, \sqsubseteq)$ be a partially ordered set and $(X, \mathrm{~d})$ be a complete cone b-metric space over a Banach algebra $\mathrm{A}$ with coefficient $\mathrm{s} \geqslant 1$. Suppose that $\mathrm{T}: \mathrm{X} \rightarrow \mathrm{X}$ is continuous and comparable and following properties hold:

(i) there exists $\alpha, \beta, \gamma \in P$ with $r(\alpha)+2 r(\beta)+2 r(s \gamma)<1$ such that $d(T x, T y) \preceq \alpha d(x, y)+\beta[d(x, T x)+$ $\mathrm{d}(\mathrm{y}, \mathrm{Ty})]+\gamma[\mathrm{d}(\mathrm{x}, \mathrm{Ty})+\mathrm{d}(\mathrm{y}, \mathrm{Tx})]$ for any comparable pair $\mathrm{x}, \mathrm{y} \in \mathrm{X}$;

(ii) there exists $x_{0} \in X$ such that $x_{0}$ and $T x_{0}$ are comparable.

Then $\mathrm{T}$ has a fixed point in $\mathrm{X}$.

Proof. Let $x_{0} \in X$ be an arbitrary point. If $T x_{0}=x_{0}$, then the proof is finished. Assume that $T x_{0} \neq x_{0}$. From condition (ii) and $T$ is comparable, we deduce that for any $j \geqslant 1, T^{j} x_{0}$ and $T^{j+1} x_{0}$ are comparable. 
Let $T^{n} x_{0}=x_{n}$, we yield $x_{j}$ and $x_{j+1}$ are comparable. From condition (i), we have

$$
\begin{aligned}
\mathrm{d}\left(x_{n+1}, x_{n}\right) & \preceq \alpha \mathrm{d}\left(x_{n}, x_{n-1}\right)+\beta\left[d\left(x_{n}, x_{n+1}\right)+d\left(x_{n-1}, x_{n}\right)\right]+\gamma d\left(x_{n-1}, x_{n+1}\right) \\
& \preceq \alpha d\left(x_{n}, x_{n-1}\right)+\beta\left[d\left(x_{n}, x_{n+1}\right)+d\left(x_{n-1}, x_{n}\right)\right]+\gamma\left[d\left(x_{n-1}, x_{n}\right)+d\left(x_{n}, x_{n+1}\right),\right.
\end{aligned}
$$

that is

$$
(e-\beta-s \gamma) d\left(x_{n+1}, x_{n}\right) \preceq(\alpha+\beta+s \gamma) d\left(x_{n}, x_{n-1}\right) .
$$

Since $r(\alpha)+2 r(\beta)+2 r(s \gamma)<1$, then $r(\beta+s \gamma) \leqslant r(\beta)+r(s \gamma)<1$, and $(e-\beta-s \gamma)$ is invertible. So we can write

$$
d\left(x_{n+1}, x_{n}\right) \preceq(e-\beta-s \gamma)^{-1}(\alpha+\beta+s \gamma) d\left(x_{n}, x_{n-1}\right)
$$

for all $n \geqslant 1$. Let $(e-\beta-s \gamma)^{-1}(\alpha+\beta+s \gamma)=k$, then

$$
d\left(x_{n+1}, x_{n}\right) \preceq \operatorname{kd}\left(x_{n}, x_{n-1}\right) .
$$

Repeating this relation we yield.

$$
d\left(x_{n+1}, x_{n}\right) \preceq k^{n} d\left(x_{1}, x_{0}\right) .
$$

From Lemma 2.15, we obtain

$$
r(\alpha+\beta+s \gamma)+r(\beta+s \gamma) \leqslant r(\alpha)+r(\beta)+r(s \gamma)+r(\beta)+r(s \gamma)=r(\alpha)+2 r(\beta)+2 r(s \gamma)<1 .
$$

That is, $\frac{r(\alpha+\beta+s \gamma)}{1-r(\beta+s \gamma)}<1$. Hence, it follows from Lemma 2.15 and 2.16 that

$$
\begin{aligned}
r(k)=r\left[(e-\beta-s \gamma)^{-1}(\alpha+\beta+s \gamma)\right] & \leqslant r\left[(e-\beta-s \gamma)^{-1}\right] r(\alpha+\beta+s \gamma) \\
& \leqslant[1-r(\beta-s \gamma)]^{-1} r(\alpha+\beta+s \gamma)=\frac{r(\alpha+\beta+s \gamma)}{1-r(\beta+s \gamma)}<1 .
\end{aligned}
$$

Now, for $m>n$ we have

$$
\begin{aligned}
d\left(x_{m}, x_{n}\right) \preceq & s d\left(x_{n}, x_{n+1}\right)+s^{2} d\left(x_{n+1}, x_{n+2}\right)+\cdots+s^{m-n-1} d\left(x_{m-2}, x_{m-1}\right)+s^{m-n-1} d\left(x_{m-1}, x_{m}\right) \\
& \preceq s k^{n} d\left(x_{1}, x_{0}\right)+s^{2} k^{n+1} d\left(x_{1}, x_{0}\right)+\cdots+s^{m-n-1} k^{m-2} d\left(x_{1}, x_{0}\right)+s^{m-n-1} k^{m-1} d\left(x_{1}, x_{0}\right) \\
& =s k^{n} d\left(x_{1}, x_{0}\right)\left[e+s k+(s k)^{2}+\cdots+(s k)^{m-1}\right] \\
& \preceq \sum_{i=1}^{\infty}(s k)^{i}\left(s k^{n}\right) d\left(x_{1}, x_{0}\right)=(e-s k)^{-1}\left(s k^{n}\right) d\left(x_{1}, x_{0}\right) .
\end{aligned}
$$

Since $r(k)<1$ implies that $\left\|k^{n}\right\| \rightarrow 0(n \rightarrow \infty)$, further, $\left\{k^{n}\right\}$ is a c-sequence. Thus from Lemma 2.11 we get that $\left\{\mathrm{sk}^{n}(e-s k)^{-1} d\left(x_{1}, x_{0}\right)\right\}$ is a c-sequence. Which shows that $\left(x_{n}\right)$ is a Cauchy sequence. Since $X$ is complete so there exists $z \in X$ such that $x_{n} \rightarrow z$ as $n \rightarrow \infty$. By the continuity of $T$ we conclude that $z$ is fixed point of $T$.

If we use the condition (iii) instead of continuity of $\mathrm{T}$ in Theorem 3.11, we have the following.

Theorem 3.12. Let $(\mathrm{X}, \sqsubseteq)$ be a partially ordered set and $(\mathrm{X}, \mathrm{d})$ be a complete cone b-metric space over a Banach algebra $\mathrm{A}$ with coefficient $\mathrm{s} \geqslant 1$. Suppose that $\mathrm{T}: \mathrm{X} \rightarrow \mathrm{X}$ is comparable and following properties hold:

(i) there exists $\alpha, \beta, \gamma \in P$ with $r(\alpha)+2 r(\beta)+2 r(s \gamma)<1$ such that $d(T x, T y) \preceq \alpha d(x, y)+\beta[d(x, T x)+$ $\mathrm{d}(\mathrm{y}, \mathrm{Ty})]+\gamma[\mathrm{d}(\mathrm{x}, \mathrm{Ty})+\mathrm{d}(\mathrm{y}, \mathrm{Tx})]$ for any comparable pair $\mathrm{x}, \mathrm{y} \in \mathrm{X}$;

(ii) there exists $x_{0} \in X$ such that $x_{0}$ and $T x_{0}$ are comparable;

(iii) if a sequence $\left\{x_{n}\right\}$ converges to $x \in X$ and for all $j \geqslant 0, x_{j}, x_{j+1}$ are comparable, then $x_{j}, x$ are comparable.

Then $\mathrm{T}$ has a fixed point in $\mathrm{X}$. 
Proof. Let $\mathrm{T}^{\mathrm{n}} \mathrm{x}_{0}=\mathrm{x}_{\mathrm{n}}$. From the proof of Theorem 3.11 it follows that $x_{n}, x_{n+1}$ are comparable for all $n \geqslant 0$ and $x_{n}$ converges to $z$. Now from condition (iii), $x_{n}, z$ are comparable. So from condition (i) we have

$$
d\left(T x_{n}, T z\right) \preceq \alpha d\left(x_{n}, z\right)+\beta\left[d\left(x_{n}, x_{n+1}\right)+d(z, T z)\right]+\gamma\left[d\left(x_{n}, T z\right)+d\left(z, x_{n+1}\right)\right] .
$$

Letting $n \rightarrow \infty$, we get

$$
d(z, T z) \preceq(\beta+\gamma) d(z, T z),
$$

that is, $(e-\beta-\gamma) \mathrm{d}(z, \mathrm{~T} z) \preceq \theta$. Then multiplying both sides with $(e-\beta-\gamma)^{-1}$, it follows that $\mathrm{d}(z, \mathrm{~T} z)=\theta$, which implies that $z$ is a fixed point of $T$.

Remark 3.13. Theorems 3.11 and 3.12 generalize Theorems 3.9 and 3.10 of [27], respectively. Indeed, take $\mathrm{s}=1$ in Theorems 3.11 and 3.12 .

Now we give two common fixed point theorems on ordered cone metric space over Banach algebras.

Theorem 3.14. Let $(\mathrm{X}, \sqsubseteq)$ be a partially ordered set and $(\mathrm{X}, \mathrm{d})$ be a complete cone b-metric space over a Banach algebra $\mathrm{A}$ with coefficient $\mathrm{s} \geqslant 1$. Suppose that $\mathrm{T}, \mathrm{S}: \mathrm{X} \rightarrow \mathrm{X}$ are two weakly comparable maps and following properties hold:

(i) there exists $\alpha, \beta, \gamma \in P$ with $r(\alpha)+2 r(\beta)+2 r(s \gamma)<1$ such that $d(T x, S y) \preceq \alpha d(x, y)+\beta[d(x, T x)+$ $\mathrm{d}(\mathrm{y}, \mathrm{Sy})]+\gamma[\mathrm{d}(\mathrm{x}, \mathrm{Sy})+\mathrm{d}(\mathrm{y}, \mathrm{Tx})]$ for any comparable pair $\mathrm{x}, \mathrm{y} \in \mathrm{X}$;

(ii) $\mathrm{T}$ or $\mathrm{S}$ is continuous.

Then $\mathrm{T}$ and $\mathrm{S}$ have a common fixed point in $\mathrm{X}$.

Proof. Let $x_{0} \in X$ be an arbitrary point. Define a sequence $\left\{x_{n}\right\}$ in $X$ as following: $T x_{2 n}=x_{2 n+1}$ and $S x_{2 n+1}=x_{2 n+2}$ for all $n \geqslant 0$. Since $T$ and $S$ are weakly comparable, then $x_{1}=T x_{0}$ and $x_{2}=S x_{1}=S T x_{0}$ are comparable. Similarly $x_{2}=S x_{1}$ and $x_{3}=T x_{2}=T S x_{1}$ are comparable, by continuing this way we obtain that $x_{n}$ and $x_{n+1}$ are comparable for all $n \geqslant 1$.

From condition (i), we have

$$
\begin{aligned}
\mathrm{d}\left(\mathrm{x}_{2 n+1}, x_{2 n+2}\right)= & \mathrm{d}\left(\mathrm{T} x_{2 n}, S x_{2 n+1}\right) \\
\preceq & \alpha \mathrm{d}\left(x_{2 n}, x_{2 n+1}\right)+\beta\left[\mathrm{d}\left(x_{2 n}, x_{2 n+1}\right)+\mathrm{d}\left(x_{2 n+1}, x_{2 n+2}\right)\right]+\gamma d\left(x_{2 n}, x_{2 n+2}\right) \\
\preceq & \alpha \mathrm{d}\left(x_{2 n}, x_{2 n+1}\right)+\beta\left[\mathrm{d}\left(x_{2 n}, x_{2 n+1}\right)+\mathrm{d}\left(x_{2 n+1}, x_{2 n+2}\right)\right] \\
& +\gamma\left[\mathrm{d}\left(x_{2 n}, x_{2 n+1}\right)+\mathrm{d}\left(x_{2 n+1}, x_{2 n+2}\right)\right],
\end{aligned}
$$

that is

$$
(e-\beta-s \gamma) d\left(x_{2 n+1}, x_{2 n+2}\right) \preceq(\alpha+\beta+s \gamma) d\left(x_{2 n}, x_{2 n+1}\right) .
$$

Since $r(\alpha)+2 r(\beta)+2 r(s \gamma)<1$, then $r(\beta+s \gamma) \leqslant r(\beta)+r(s \gamma)<1$, and $(e-\beta-s \gamma)$ is invertible. So we can write

$$
\mathrm{d}\left(\mathrm{x}_{2 \mathrm{n}+1}, x_{2 n+2}\right) \preceq(e-\beta-s \gamma)^{-1}(\alpha+\beta+s \gamma) \mathrm{d}\left(x_{2 n}, x_{2 n+1}\right)
$$

for all $n \geqslant 1$. Let $(e-\beta-s \gamma)^{-1}(\alpha+\beta+s \gamma)=k$, then

$$
d\left(x_{2 n+1}, x_{2 n+2}\right) \preceq k d\left(x_{2 n}, x_{2 n+1}\right) .
$$

Repeating this relation we yield

$$
d\left(x_{n+1}, x_{n}\right) \preceq k^{n} d\left(x_{1}, x_{0}\right) .
$$

Now, for $m>n$ we have

$$
\begin{aligned}
\mathrm{d}\left(x_{\mathrm{m}}, x_{n}\right) \preceq & s d\left(x_{n}, x_{n+1}\right)+s^{2} d\left(x_{n+1}, x_{n+2}\right)+\cdots+s^{m-n-1} d\left(x_{m-2}, x_{m-1}\right)+s^{m-n-1} d\left(x_{m-1}, x_{m}\right) \\
& \preceq s k^{n} d\left(x_{1}, x_{0}\right)+s^{2} k^{n+1} d\left(x_{1}, x_{0}\right)+\cdots+s^{m-n-1} k^{m-2} d\left(x_{1}, x_{0}\right)+s^{m-n-1} k^{m-1} d\left(x_{1}, x_{0}\right) \\
& =s k^{n} d\left(x_{1}, x_{0}\right)\left[e+s k+(s k)^{2}+\cdots+(s k)^{m-1}\right]
\end{aligned}
$$




$$
\preceq \sum_{i=1}^{\infty}(s k)^{i}\left(s k^{n}\right) d\left(x_{1}, x_{0}\right)=(e-s k)^{-1}\left(s k^{n}\right) d\left(x_{1}, x_{0}\right) .
$$

From the proof of Theorem 3.11 we have $r(k)<1$, so $\left\|k^{\mathfrak{n}}\right\| \rightarrow 0(n \rightarrow \infty)$. So we have

$$
\left.\left\|(e-s k)^{-1}\left(s k^{n}\right) d\left(x_{1}, x_{0}\right)\right\| \leqslant\left\|(e-s k)^{-1}\right\|\|s\| \| k^{n}\right)\|\| d\left(x_{1}, x_{0}\right) \| \rightarrow 0(n \rightarrow \infty) .
$$

By lemma 2.14, for any $c \in A$ with $\theta \ll c$, there exists $N \in \mathbb{N}$ such that for any $m>n>N$,

$$
\mathrm{d}\left(\mathrm{x}_{\mathrm{m}}, \mathrm{x}_{\mathrm{n}}\right) \ll \mathrm{c},
$$

which shows that $\left(x_{n}\right)$ is a Cauchy sequence. Since $X$ is complete so there exists $z \in X$ such that $x_{n} \rightarrow z$ as $n \rightarrow \infty$. Without loss of generality, we can assume that $T$ is continuous. Then it is clear that $T z=z$. Since $z, z$ are comparable from condition (i), we have

$$
\mathrm{d}(\mathrm{T} z, \mathrm{Sz}) \preceq \alpha \mathrm{d}(z, z)+\beta[\mathrm{d}(z, \mathrm{~T} z)+\mathrm{d}(z, S z)]+\gamma \mathrm{d}(z, \mathrm{~T} z)+\mathrm{d}(z, S z), \quad \mathrm{d}(z, S z) \preceq(\beta+\gamma) \mathrm{d}(z, S z),
$$

that is,

$$
(e-\beta-\gamma) \mathrm{d}(z, S z) \preceq \theta .
$$

Multiplying both sides by $(e-\beta-\gamma)^{-1}$, we get $d(z, S z)=\theta$. Therefore, $T z=S z=z$ that is, $z$ is common fixed point of $T$ and $S$.

If we use the condition (ii) instead of continuity of $\mathrm{T}$ or $\mathrm{S}$ in Theorem 3.14, we have the following.

Theorem 3.15. Let $(\mathrm{X}, \sqsubseteq)$ be a partially ordered set and $(\mathrm{X}, \mathrm{d})$ be a complete cone b-metric space over a Banach algebra $\mathrm{A}$ with coefficient $\mathrm{s} \geqslant 1$. Suppose that $\mathrm{T}, \mathrm{S}: \mathrm{X} \rightarrow \mathrm{X}$ are two weakly comparable maps and following properties hold:

(i) there exists $\alpha, \beta, \gamma \in P$ with $r(\alpha)+2 r(\beta)+2 r(s \gamma)<1$ such that $\mathrm{d}(\mathrm{Tx}, \mathrm{Sy}) \preceq \alpha \mathrm{d}(\mathrm{x}, \mathrm{y})+\beta[\mathrm{d}(\mathrm{x}, \mathrm{Tx})+$ $\mathrm{d}(\mathrm{y}, \mathrm{Sy})]+\gamma[\mathrm{d}(\mathrm{x}, \mathrm{Sy})+\mathrm{d}(\mathrm{y}, \mathrm{T} x)]$ for any comparable pair $\mathrm{x}, \mathrm{y} \in \mathrm{X}$;

(ii) if a sequence $\left\{x_{n}\right\}$ converges to $x \in X$ and for all $j \geqslant 0, x_{j}, x_{j+1}$ are comparable, then $x_{j}, x$ are comparable.

Then $\mathrm{T}$ and $\mathrm{S}$ have a common fixed point in $\mathrm{X}$.

Proof. It can be proved in the same way as Theorems 3.12 and 3.14 .

\section{Acknowledgment}

I would like to express my sincere thanks and appreciation to Prof. Dr. Nawab Hussain who helped me at various stages of this work.

\section{References}

[1] M. Abbas, G. Jungck, Common fixed point results for noncommuting mappings without continuity in cone metric spaces, J. Math. Anal. Appl., 341 (2008), 416-420. 1

[2] M. Al-Khaleel, S. Al-Sharifa, M. Khandaqji, Fixed points for contraction mappings in generalized cone metric spaces, Jordan J. Math. Stat., 5 (2012), 291-307. 2

[3] I. Altun, G. Durmaz, Some fixed point theorems on ordered cone metric spaces, Rend. Circ. Mat. Palermo (2), 58 (2009), 319-325. 1, 2.5, 2.17, 2.19

[4] I. Altun, H. Simsek, Some fixed point theorems on ordered metric spaces and application, Fixed Point Theory Appl., 2010 (2010), 17 pages. 1

[5] I. A. Bakhtin, The contraction mapping principle in almost metric spaces, Funct. Anal., 30 (1989), 26-37. 1

[6] F. Bojor, Fixed point of $\phi$-contraction in metric spaces endowed with a graph, An. Univ. Craiova Ser. Mat. Inform., 37 (2010), 85-92.

[7] N. Bourbaki, Topologie Générale, Herman, Paris, (1971). 1 
[8] H. Çakallı, A. Sönmez, Ç. Genç, On an equivalence of topological vector space valued cone metric spaces and metric spaces, Appl. Math. Lett., 25 (2012), 429-433. 1

[9] S. Czerwik, Contraction mappings in b-metric spaces, Acta Math. Inform. Univ. Ostraviensis, 1 (1993), 5-11. 1

[10] W.-S. Du, A note on cone metric fixed point theory and its equivalence, Nonlinear Anal., 72 (2010), 2259-2261. 1

[11] J. Harjani, K. Sadarangani, Generalized contractions in partially ordered metric spaces and applications to ordinary differential equations, Nonlinear Anal., 72 (2010), 1188-1197. 1

[12] H. P. Huang, S. Radenović, Common fixed point theorems of generalized Lipschitz mappings in cone b-metric spaces over Banach algebras and applications, J. Nonlinear Sci. Appl., 8 (2015), 787-799. 1, 2.7, 2.8, 2.9

[13] L.-G. Huang, X. Zhang, Cone metric spaces and fixed point theorems of contractive mappings, J. Math. Anal. Appl., 332 (2007), 1468-1476. 1, 2

[14] N. Hussain, A. M. Al-Solami, M. A. Kutbi, Fixed points of $\alpha$-admissible mappings in cone b-metric spaces over Banach algebra, J. Math. Anal., 8 (2017), 89-97.

[15] N. Hussian, M. H. Shah, KKM mappings in cone b-metric spaces, Comput. Math. Appl., 62 (2011), 1677-1684. 1

[16] Z. Kadelburg, M. Pavlović, S. Radenović, Common fixed point theorems for ordered contractions and quasicontractions in ordered cone metric spaces, Comput. Math. Appl., 59 (2010), 3148-3159. 1

[17] Z. Kadelburg, S. Radenovic, A note on various types of cones and fixed point results in cone metric spaces, Asian J. Math. Appl., 2013 (2013), 7 pages. 2.10

[18] M. A. Khamsi, N. Hussain, KKM mappings in metric type spaces, Nonlinear Anal., 73 (2010), 3123-3129.

[19] M. A. Kutbi, J. Ahmed, A. E. Al-Mazrooei, N. Hussain, Multivalued fixed point theorem in cone b-metric space over Banach algebra with Application, J. Math. Anal., 9 (2018), 52-64. 2.1

[20] H. Liu, S. Y. Xu, Cone metric spaces with Banach algebras and fixed point theorems of generalized Lipschitz mappings, Fixed Point Theory Appl., 2013 (2013), 10 pages. 1, 2.6

[21] S. Radenović, B. E. Rhoades, Fixed point theorem for two non-self mappings in cone metric spaces, Comput. Math. Appl., 57 (2009), 1701-1707. 1, 2.12, 2.13, 2.14

[22] T. Rasham, A. Shoaib, M. Arshad, Fixed Point Results for Locally Hardy Rogers-Type Contractive Mappings for Dislocated Cone Metric Space, TWMS J. Pure Appl. Math., 10 (2019), 76-82. 1

[23] S. Rezapour, R. Hamlbarani, Some notes on the paper: "Cone metric spaces and fixed point theorems of contractive mappings", J. Math. Anal. Appl., 345 (2008), 719-724. 1

[24] W. Rudin, Functional Analysis, McGraw-Hill, New York, (1991). 2, 2.2, 2.3

[25] A. Shoaib, P. Kumam, A. Shahzad, S. Phiangsungnoen, Q. Mahmood, Fixed point results for fuzzy mappings in a b-metric space, Fixed Point Theory Appl., 2018 (2018), 12 pages. 1

[26] S. Y. Xu, S. Radenović, Fixed point theorems of generalized Lipschitz mappings on cone metric spaces over Banach algebras without assumption of normality, Fixed Point Theory Appl., 2014 (2014), 12 pages. 1, 2.11, 2.15, 2.16

[27] Q. Yan, J. D. Yin, T. Wang, Fixed point and common fixed point theorems on ordered cone metric spaces over Banach algebras, J. Nonlinear Sci. Appl., 9 (2016), 1581-1589. 2.20, 3.13 